\title{
Informality: the Doorstep of the Legal System
}

https://doi.org/10.1515/openec-2017-0004

Received February 17, 2017; accepted July 11, 2017

\begin{abstract}
Many entrepreneurs work informally because it is costly to start and run a business legally. Using a dynamic model of industry equilibrium, I show that the costs of the legal system can explain the cross country variability of the size of the informal economy. The model implies that the business start-up costs are more important than taxes and labor market regulations. Small, less productive, entrepreneurs, facing high entry costs, start informally, waiting to become more productive before legalizing. Informality is often the doorstep of the legal system.
\end{abstract}

Keywords: Informality; Entry; Regulation; Start-up

JEL: 017, L51

\section{Introduction}

Why do many entrepreneurs work in the informal economy, outside the legal system? One plausible, albeit obvious, answer is that working inside the legal system is costly. These costs of the legal system can be crudely classified into two macro categories: operational costs, that arise because legal firms must comply with many laws and regulations, and start-up costs, that include the one-time fees required to legally open a business and the costs of going through the related bureaucratic procedures. In this paper I propose a dynamic model of industry equilibrium to study the effects of both operational and start-up costs of on the size and cross country variability of the informal economy. Together with the business start-up costs identified by Djankov et al. (2002), I consider two operational costs: taxes and labor market regulations. The main result of the analysis is that start-up costs matter more than taxes and labor market regulations.

The model that I propose builds on Hopenhayn (1992) and Hopenhayn and Rogerson (1993) and extends it to an economy with taxation and with two sectors, the legal and the informal. Legal and informal firms coexist and informals can legalize with the payment of a fixed start-up cost. These new features still deliver a tractable framework, with a rich characterization of the firms' dynamics in both sectors. More generally, the model allows me to build a theory of informality based on firm dynamics, which is new to the literature. In particular, the numerical analysis shows that if start-up costs are high, then smaller, less productive, firms can only start informally, waiting to become more productive and to grow before legalizing. This behavior is consistent with the idea of entrepreneurship first formalized by Jovanovic (1982), according to which the only way for potential entrepreneurs to learn about their efficiency is entering the market. Upon entry, they survive and grow only in case they are productive and exit otherwise. My model with an informal sector implies that if it is too costly to do this learning process in the legal sector, because of the start-up costs, then some of the potential entrepreneurs will choose to do it in the informal sector. In this respect, the model implies a view of the informal sector as the Doorstep of the official one.

The model implies that the start-up costs explain roughly $75 \%$ of the cross country variability of the informal economy, while operational costs only $25 \%$. I obtain this result feeding in the model the empirical measures of the costs and analyzing the resulting cross section of the informal economy. The great advantage

`Corresponding Author: Francesco Flaviano Russo: University of Naples Federico II and CSEF. Via Cinthia, Monte Sant' Angelo, 80126, Napoli, Italy, Tel. (+39) 081675276, E-mail: francescoflaviano.russo@unina.it 
of my numerical methodology is that, using a structural model, I am able to isolate the effect of start-up and operational costs from potential confoundings, unlike previous empirical works.

The open question, then, is how to validate the model. First, I show that the characteristics of the informal sector delivered by the model are consistent with the available survey evidence. In particular, informal firms are smaller and less productive than their legal counterparts and a very small number of them survives in the market. The ones that survive are the most productive, which grow and, relatively quickly, legalize. This implies that, in each period, only a small fraction of existing legal firms started as informal. To independently validate my cross country exercise, I also show that the simulated cross section of the informal economy is very similar to the empirical measures obtained with several estimation methods.

The rest of the paper is organized as follows: Section 2 briefly summarizes the related literature. Section 3 describes the model. Section 4 clarifies the details of the simulation. Section 5 describes the main properties of the model and their relationship with the available survey evidence. The key results are discussed in section 6. The empirical validation of the numerical exercise is the subject of section 7 . In section 8 I analyze the robustness of the model results to alternative assumptions. Section 9 concludes. A companion appendix, available upon request, documents extensively the properties of the model and the algorithm used to compute the equilibrium. The appendix also includes two model extensions: to labor taxation and to productivity enhancing public goods for legal firms.

\section{Related Literature}

The analysis of the informal (hidden, shadow) economy is the subject of a rapidly spreading literature, following the Rational Choice tradition initiated by Becker (1978) and fundamentally inspired by the work of DeSoto (1989), who first extensively analyzed and described the life of the informal entrepreneurs in the city of Lima.

The closest work to my analysis is D'Erasmo and Moscoso Boedo (2012). Their paper develops a model of informality with financial frictions and use it to explain the TFP differentials across countries. In their model the choice for a firm between the formal and informal sector is irreversible, against the available empirical evidence summarized by Maloney (2004), De Paula and Scheinkman (2008) and LaPorta and Shleifer (2008). In contrast, in my model informal firms are allowed to switch to the legal sector upon the payment of a startup cost, consistently with the above evidence. This feature allows me to build a theory of informality based on firm dynamics, which is the main contribution of my work.

Another closely related work is Antunes and Cavalcanti (2007). In a static model with credit constraints for informal firms, they study how the enforcement of financial contracts and the regulation costs affect the informal economy. They find that regulation costs account for most of the observed empirical differences between the US and Europe. Differently from their work, I use a dynamic model of entry and exit, that allows a clear separate identification of the start-up from a fixed, per period, cost of production. In addition, with my dynamic framework I can keep track of the changes in the distribution of firms in the legal and informal sectors and analyze the characteristics of new start-ups. However, I do not have financial constraints in my model. In a related contribution, Prado (2011) also studies the effect of regulation, enforcement and taxation on the size of the informal economy within a static model.

On the empirical side, previous existing works, recently summarized by Straub (2005), already showed that high start-up costs are correlated with large informal sectors, but found only weak evidence for the relationships between labor regulations and informality and between taxes and informality. The first fact has been extensively documented by Djankov, LaPorta, Lopez de-Silanes and Shleifer (2002), who built a data set that identifies all the business start-up costs for a large cross section of countries. Using the same data, Auriol and Warlters (2005) similarly report a positive and significant effect of start-up costs on the size of the informal economy. In a more recent contribution, Estrin and Mickiewicz (2012) study the relationship between entry and the size of the informal economy empirically. They find that bigger informal sectors predict lower entry rates in the legal sector, which implies that the competition from informals lowers the incentives 
to start a new business legally. The second fact emerges from the work by Botero, Djankov, LaPorta, Lopez de-Silanes and Shleifer (2004). After collecting a comprehensive data set on labor market regulations, they were unable to find any systematic relationship with the size of the informal economy. A similar result appears in Besley and Burgess (2004), where a pro-worker legislation is shown to be positively associated with the size of the informal sector in a panel of Indian states. The relationship between taxes and informality is much more controversial. Among others, Johnson, Kaufmann and Zoido-Lobaton (1998) find evidence of a positive association between taxes and the size of the informal economy, but Friedman, Johnson, Kaufmann and Zoido-Lobaton (2000), with a different empirical strategy, found a negative association. Lemieux, Fortin and Frechette (1994) and Davis and Henrekson (2004) also report ambiguous results. The main difference between my work and all of these empirical contributions is methodological: I employ a dynamic structural model to study the contribution of different costs numerically. The main advantage of my methodology is that, using a structural model, I can isolate the effects of the single costs better. This is particularly important in the context of a cross country analysis, where the problem of omitted variables is particularly pervasive.

Recent contributions on the informal economy also include: Sarte (2000), who studies the effect of informality on growth in the presence of rent-seeking bureaucrats; Azuma and Grossman (2002), who show how the Government, in the presence of unobservable endowments, can extract from producers such a high amount to force the poorly endowed in the informal sector; Dessy and Pallage (2003), who propose a model with strategic complementarities where legal firms pay taxes that finance the provision of a productivity enhancing good; Fugazza and Jacques (2003), who develop a matching model of the labor market with formal and informal workers, showing that policies which encourage the participation in the legal sector are more effective than deterrence; Busato and Chiarini (2004), who develop a business cycle model with a legal and an informal sector to stress the risk sharing opportunities allowed by the reallocation of labor supply across sectors; Maloney (2004), who studies the informal sector empirically in Latin America highlighting its entrepreneurial nature; Gerxhani (2004), who compares the informal sectors in developed and less developed countries; Choi and Thum (2005), who show how the option for an entrepreneur to produce illegally reduces the rents that corrupt public officials can extract; Amaral and Quintin (2006), who show that informal firms substitute low-skilled labor for physical capital because of financial constraints; Dabla-Norris, Gradstein and Inchauste (2008), who show, empirically, that the quality of the legal system is an important determinant of informality; De Paula and Scheinkman (2008), who build equilibrium models of informality and test them on a survey of Brazilian firms, showing that informality spreads along the supply chain in the presence of VAT collected with the credit system; La Porta and Shleifer (2008), who show, with survey data, that informal firms are inefficient, less capitalized and worse managed than legal firms; Blackburn, Bose and Capasso (2012), who highlight the trade-off between evading taxes and offering collateral for investments, which means that the incentive to evade taxes is higher in less financially developed countries; Capasso and Jappelli (2013), who also show, empirically, a negative relationship between financial development and tax evasion as a consequence of the trade-off between tax evasion and the necessity to have collateral for investments; Ordonez (2014), who builds a general equilibrium model to show how incomplete tax enforcement decreases aggregate productivity and output.

\section{The Model}

The model builds on the framework developed by Hopenhayn (1992) and Hopenhayn and Rogerson (1993) (HR henceforth) and extends it to an economy composed of two sectors: the legal, where the firms comply with all the laws and regulations, and the informal, where they don't. The goods produced in the two sectors share the same characteristics but, since they are produced with different technologies (say in a regular factory or 
in a residential basement) and since they are sold in two different markets ${ }^{1}$ (for instance a regular shop or an occasional street vendor-peddler), they fetch different prices. This feature implies that the model completely abstracts from intrinsically illegal products: a good produced in the informal sector would be perfectly legal if produced within the legal sector.

Legal firms must pay three different operational costs associated with the legal system: a fixed cost $c^{f}$ because of the necessity to comply with all relevant laws and regulations, that either involve a fee or a time consuming bureaucratic procedure, a proportional firing cost, or severance payment, $\phi$ and a proportional $\operatorname{tax} \tau^{y}$ on each unit of output produced. The profit of a legal firm $j$ at time $t$ is:

$$
p_{t}\left(1-\tau^{y}\right) f\left(n_{j t}, a_{j t}\right)-w_{t} n_{j t}-c^{f}-\phi I_{\left\{n_{j t-1} \geq n_{j t}\right\}}\left(n_{j t-1}-n_{j t}\right)
$$

where $I$ is the indicator function, $p_{t}$ is the price of the good in the legal market, $w_{t}$ the wage rate and $f\left(n_{j t}, a_{j t}\right)$ the production function, that depends upon employment $n_{j t}$ and upon the level of an idiosyncratic technological shock $a_{j t}$. To keep the model simple, I assume, as in HR, a power specification for the production function, with $f\left(n_{j t}, a_{j t}\right)=e^{a_{j t}} n_{j t}^{\alpha}$ and a Markov process for the exogenous technological shock, as described by the transition function $F\left(a_{j t}, a_{j t+1}\right)$. Importantly, the inclusion of the fixed cost $c^{f}$, as in HR, is fundamental to distinguish between exiting firms and firms that do not produce output, which allows to meaningfully talk about firm's exit. The last term in expression (1) is the firing cost, modeled, as in HR, as a proportional (severance) payment $\phi$ on the difference between the previous and the actual level of employment, whenever this difference is positive (i.e. in case of a reduction of labor input). I do not include hiring costs in the model because their impact on the model equilibrium is qualitatively similar to firing costs (they lower the discounted value of future profits, reducing the size and growth rate of legal businesses) but quantitatively modest, since they become relevant only when the firm is hit by a positive productivity shock, that increases the profits and makes the firm more willing to pay them.

The informal sector of the economy is the new feature of my model. First of all, informal firms are not subject to severance payments and, therefore, they can freely fire workers without any extra cost. In addition, informal firms do not pay taxes, but are subject to random audits ${ }^{2}$ that, with exogenous probability $\pi$, result in the seizure of the output. Alternatively, I could have assumed that, upon auditing, the informal firm would have been forced to pay the output tax, perhaps with some proportional fine. I assume, instead, the seizure of the production because I want to distinguish my model of informal production from a model of tax evasion. This feature of the model also differentiates it from D’Erasmo and Moscoso Boedo (2012), that do not have enforcement. The profit of an informal firm $k$ at time $t$ is:

$$
q_{t}(1-\pi) f^{i}\left(n_{k t}^{i}, a_{k t}\right)-w_{t}^{i} n_{k t}^{i}-c^{i}
$$

where $q_{t}$ is the price in the informal market and $f^{i}\left(n_{k t}^{i}, a_{k t}\right)$ the production function for informal firms. I further assume that $y_{t}^{i}=e^{a_{k t}}\left(n_{k t}^{i}\right)^{\eta}$, where $a_{k t}$ follows the same process of the shock hitting the legal firms. Even if informal firms do not comply with any kind of regulation, they still face a fixed cost $c^{i}$ for producing in the informal sector, the (fixed) Cost of Informality. As first stressed by DeSoto (1989), informals employ a lot of resources to avoid detection. There are both explicit expenditures, like the bribes to the government officials that are supposed to audit, and implicit costs, for instance because they cannot reach economies of scale to avoid visibility. Informals also transfer resources to Mafia-like organizations that replace the government as providers of protection and contract enforcement, or just as a consequence of extortion ${ }^{3}$. Further fixed costs

\footnotetext{
1 Evidence from the Informal Survey and from the Micro Survey implemented by the World Bank suggests that the markets for legal and informal goods are different. See La Porta and Shleifer (2008).

2 In this respect the model is very stylized because it does not consider the effect of size on enforcement probability, i.e. the fact that bigger firms are easier to audit and more visible, which gives the entrepreneurs an incentive to remain small. Ordonez (2013) provides a model in which he studies such interactions and, in general, the effects of enforcement on the legal and illegal sector. 3 Legal businesses also transfer resources to such organizations. In fact the primary source of revenue for organizations like the Sicilian Mafia, the Camorra (based in Campania, a region in southern Italy) or the N'drangheta (mainly operating in Calabria, southern Italy) is from extortions on legal businesses, typically under the treat of violence.
} 
of informality are the impossibility to access legal courts, for contract enforcement and dispute resolution, and the difficulty to obtain external financing. In this respect, the model is very stylized, since I use just one fixed cost as a reduced form to model several features that I do not consider explicitly. The reason why I chose this strategy is because I want to have a tractable model with a manageable computational procedure. For instance, modeling financing constraint, perhaps adding a financial sector and the choice between internal and external finance, would have complicated the framework and the solution procedure. In addition, it would have made the comparative statics much more difficult. Modeling the access to courts, on the other hand, would have required a more complicated contracting environment, again complicating the framework. Furthermore, the importance of these omitted factors is not clearly established. For financing constraints, for instance, there is evidence that small firms are financially constrained even if they are legal. Therefore, for a new start-up, which is typically small, the lower cost of credit, or its greater availability, is not an important factor in the choice between starting legally or informally. The inability to access to courts is also unlikely to be a significant cost for informal businesses in countries where the judicial trials are long and uncertain, perhaps also subject to capture or corruption.

To keep the model as simple as possible, I assume that the legal production is a function of a legal labor input $n_{t}$ only and, similarly, that the informal production is a function of an informal labor input $n_{t}^{i}$ only. In practice, it is often the case that legal firms employ part of their labor force informally. In this sense the model is different from a tax evasion model, where the firms optimally choose how much of their production and profits to report to the tax administration and how many of their workers to hire regularly. In my model, the entrepreneurs can only choose to be completely legal or illegal. This assumption is what allows me to solve the model (relatively) easily for the stationary distributions of legal and illegal firms.

At the beginning of each period, incumbent firms in the legal sector choose whether to stay in the sector or exit, as in HR. Incumbent informal firms, conversely, choose whether to stay in the informal sector, exit from the market or legalize their activities, switching to the legal sector upon the payment of a fixed cost $c^{e}$. The possibility for informal firms to switch to the legal sector is the crucial new element of my model, that differentiates it from other similar contributions such as Antunes and Cavalcanti (2007) and D'Erasmo and Moscoso Boedo (2012). In addition, this feature is what allows me to develop a theory of informality based on firm dynamics. The legal start-up costs $c^{e}$ include both the monetary payments required to legally start a business and the opportunity cost to comply with all the mandatory bureaucratic procedures. Informal firms that are audited face a more restricted choice set and must either legalize or exit. Legal firms that exit must pay the firing cost (which can be zero, in case of no labor market regulation), while no payment is due by exiting informals. Consistently with the choice of having either fully legal or fully illegal firms, with the only difference being a registration (upon the payment of the entry cost), I model the choice of legalizing an informal activity as irreversible: legal firms are not allowed to disappear from the legal market and to start producing informally. As it will be clear later, in the model the legal firms are, on average, big, both in terms of output and in terms of employment. This means that they are visible. Thus it seems artificial to assume that they can suddenly hide their operation completely, since this implies a cancellation from all the public registers while they are still on the market, perhaps on a smaller scale than before. Nevertheless, in the context of this model, this is not really an assumption: for many realistic parameterizations, legal firms never choose to switch to the informal sector, even if they are allowed to do so. In particular, changing the model assumption and allowing legal firms to become informal, still results in an almost zero rate of legal firms moving to the informal sector. Basically, since legal firms are big and productive, and since productivity is persistent, they simply keep producing legally unless the productivity shock is very small, in which case it is better to close down altogether because they will not be profitable even in the informal sector. Firms that stay in each market pay the corresponding fixed cost, observe the productivity shock and choose the optimal level of production and labor. The value function of a legal firm $j$ is:

$$
\begin{gathered}
W\left(a_{j t}, n_{j t} ; p_{t}\right)=\max _{n_{j t+1}}\left\{p_{t}\left(1-\tau^{y}\right) f\left(n_{j t+1}, a_{j t}\right)-w_{t} n_{j t+1}-c^{f}-\phi I_{\left\{n_{j t} n_{j t+1}\right\}}\left(n_{j t}-n_{j t+1}\right)\right. \\
\left.+\beta \max \left[-\phi n_{j t+1} ; E_{a} W\left(a_{j t+1}, n_{j t+1} ; p_{t}\right)\right]\right\}
\end{gathered}
$$


The value function of an informal firm $k$ is instead:

$$
\begin{aligned}
V\left(a_{k t} ; q_{t}, p_{t}\right)=\max _{n_{k t+1}^{i}}\left\{q_{t}(1-\pi) f^{i}\left(n_{k t+1}^{i}, a_{k t}\right)-w_{t}^{i} n_{k t+1}^{i}-c^{i}+\pi \beta \max \left[0 ; E_{a} W\left(a_{k t+1}, n_{k t+1}^{i} ; p_{t}\right)-c^{e}\right]\right. \\
\left.+(1-\pi) \beta \max \left[0 ; E_{a} V\left(a_{k t+1} ; q_{t}, p_{t}\right) ; E_{a} W\left(a_{k t+1}, n_{k t+1}^{i} ; p_{t}\right)-c^{e}\right]\right\}
\end{aligned}
$$

If the informal firm is not audited (with probability $1-\pi$ ), then it switches to the legal sector if the expected present value of a legal business, net of the entry cost, is bigger than the expected present value of an informal business $\left(E_{a} W-c^{e}>E_{a} V\right)$. If the opposite is true, then it is better to stay in the informal sector. If neither of the two expected values is positive $\left(0>E_{a} W-c^{e}\right.$ and $\left.0>E_{a} V\right)$, then the best choice is to exit from the market. Audited firms (with probability $\pi$ ) do not have the option to stay in the informal sector.

In each period there is a large number of potential entrants in both sectors. Entry in the informal sector is free, while entry in the legal sector is conditional on the start-up cost $c^{e}$. As in $\mathrm{HR}$, the current value of the productivity shock for new entrants in the legal sector is drawn from the $\operatorname{pdf} v(a)$. I make the same assumption also for new start-ups in the informal sector. The expected values of entry are:

$$
W^{e}\left(p_{t}\right)=\int W\left(a_{t}, 0 ; p_{t}\right) d v\left(a_{t}\right)
$$

and

$$
V^{e}\left(q_{t}, p_{t}\right)=\int V\left(a_{t} ; q_{t}, p_{t}\right) d v\left(a_{t}\right)
$$

A potential entrepreneur will start legally only if the value of entry in the legal sector $W^{e}$, net of the entry $\operatorname{cost} c^{e}$, is bigger than the value of entry in the informal $V^{e}$.

The economy is also populated by a set of identical households. The main difference with HR is that, in my framework, households own both legal and informal firms, supply legal or informal indivisible labor and buy goods in both markets. Differently from D'Erasmo and Moscoso Boedo (2012), I explicitly differentiate the good produced in the legal sector from the good produced in the informal sector. Similarly to HR, households have access to markets to diversify the idiosyncratic risk, so that the economy is equivalent to another economy with a representative household and the following intra-temporal utility function:

$$
\sum_{t=0}^{\infty} \beta^{t} u\left(\hat{c}_{t}, l_{t}\right)
$$

The per period utility function is $u\left(\hat{c}_{t}, l_{t}\right)=\log \hat{c}_{t}+H l_{t}$. It is defined over leisure $l_{t}=1-N_{t}-N_{t}^{i}$, which is the difference between 1 and total labor supplied in the legal $\left(N_{t}\right)$ and informal $\left(N_{t}^{i}\right)$ sectors, and over the composite consumption good $\hat{c}_{t}$. The consumption good is in turn a function of the consumption of the legal good $c_{t}$ and of the informal good $c_{t}^{i}$, as determined by the following CES aggregator:

$$
\hat{c}_{t}=\left[\psi c_{t}^{z}+(1-\psi) c_{t}^{i z}\right]^{\frac{1}{z}}
$$

The budget constraint of the household is the following:

$$
p_{t} c_{t}+q_{t} c_{t}^{i}=w_{t} N_{t}+w_{t}^{i} N_{t}^{i}+\Pi_{t}+\Pi_{t}^{i}+T_{t}
$$

where $\Pi_{t}$ are the aggregate profits from the legal firms, $\Pi_{t}^{i}$ the aggregate profits from the informal firms and $T_{t}$ the lump sum transfers from the government. Importantly, $T_{t}$ does not include the payments of the startup costs, that are, therefore, a pure waste of resources. In addition, in this baseline model specification I assume the absence of taxation on labor ${ }^{4}$. I denote the optimal levels of consumption, obtained solving the household problem, as $C\left(p_{t}, q_{t}, \Pi_{t}, \Pi_{t}^{i}, T_{t}\right)$ and $C^{i}\left(p_{t}, q_{t}, \Pi_{t}, \Pi_{t}^{i}, T_{t}\right)$, while the optimal labor supplies as $N\left(p_{t}, q_{t}, \Pi_{t}, \Pi_{t}^{i}, T_{t}\right)$ and $N^{i}\left(p_{t}, q_{t}, \Pi_{t}, \Pi_{t}^{i}, T_{t}\right)$.

4 In appendix I show that the inclusion of labor taxation does not significantly alter the results. 
The state of the economy in each period is summarized by two measures of legal and informal firms, $\mu_{t}\left(a_{t}, n_{t}\right)$ and $\mu_{t}^{i}\left(a_{t}, n_{t}^{i}\right)$. Given the firms' optimal decisions rules, obtained by solving their optimization problems, it is possible to characterize the dynamic behavior of these two measures. I denote with $X\left(a_{t}, n_{t} ; p_{t}\right)$ an indicator function that is equal to 1 in case the legal firm chooses to stay in the market (and zero if the decision is to exit). I also denote with $X^{i}\left(a_{t} ; q_{t}, p_{t}\right)$ an indicator function that is equal to 1 if the informal firm chooses to stay in the informal sector (and zero if the decision is to exit or switch to the legal sector) and with $\chi\left(a_{t} ; q_{t}, p_{t}\right)$ an indicator function that is equal to 1 if the informal firm chooses to switch to the formal sector (and zero if the decision is to exit or to stay in the informal sector). In both cases I assume that, if a firm is indifferent between stay and exit or stay and switch, it stays. Then I can summarize the evolution of the state of the economy with the following mappings defined over the measures $\mu$ and $\mu^{i}$ :

$$
\begin{aligned}
\mu_{t+1}\left(a_{t+1}, n_{t+1}\right)= & \int \mu_{t}\left(a_{t}, n_{t}\right) I_{\left\{N\left(a_{t}, n_{t} ; p_{t}\right)=n_{t+1}\right\}} X\left(a_{t}, n_{t} ; p_{t}\right) d F\left(a_{t}, a_{t+1}\right) \\
& +B \int I_{\left\{N\left(a_{t}, 0 ; p_{t}\right)=n_{t+1}\right\}} d v\left(a_{t}\right) \\
& +\int \mu_{t}^{i}\left(a_{t}, n_{t}^{i}\right) I_{\left\{N^{i}\left(a_{t} ; q_{t}, p_{t}\right)=n_{t+1}\right\}} \chi\left(a_{t} ; q_{t}, p_{t}\right) d F\left(a_{t}, a_{t+1}\right) \\
\mu_{t+1}^{i}\left(a_{t+1}, n_{t+1}^{i}\right)= & \int \mu_{t}^{i}\left(a_{t}, n_{t}^{i}\right) I_{\left\{N^{i}\left(a_{t} ; q_{t}, p_{t}\right)=n_{t+1}^{i}\right\}} X^{i}\left(a_{t} ; q_{t}, p_{t}\right) d F\left(a_{t}, a_{t+1}\right) \\
& +B^{i} \int I_{\left\{N^{i}\left(a_{t} ; q_{t}, p_{t}\right)=n_{t+1}^{i}\right\}} d v\left(a_{t}\right)
\end{aligned}
$$

where $B$ and $B^{i}$ are the effective mass of entrants in the official and informal sectors and where $N\left(a_{t}, n_{t} ; p_{t}\right)$ and $N^{i}\left(a_{t} ; q_{t}, p_{t}\right)$ are, respectively, the optimal choices of labor input by official and informal firms in period $t$. In each of the above expressions, the first term is the contribution of incumbent firms that choose to stay in the market and the second term is the contribution of new entrants. The third term in the first expression is the contribution of informal firms that switch to the legal sector. With a slight abuse of notation I define, for each period, $\Theta_{t}=\left\{p_{t}, B\right\} . \Theta_{t}^{i}=\left\{q_{t}, B^{i}\right\}$. The transition functions become: $\mu_{t+1}=\Psi\left(\Theta_{t}, \Theta_{t}^{i}, \mu_{t}, \mu_{t}^{i}\right), \mu_{t+1}^{i}=$ $\Psi^{i}\left(\Theta_{t}^{i}, p_{t}, \mu_{t}^{i}\right)$.

I denote the aggregate output in the legal and informal sector as $Y\left(\Theta_{t}, \Theta_{t}^{i}, \mu_{t}, \mu_{t}^{i}\right)$ and $Y^{i}\left(\Theta_{t}, \Theta_{t}^{i}, \mu_{t}, \mu_{t}^{i}\right)$ and the labor demands as $L_{d}\left(\Theta_{t}, \Theta_{t}^{i}, \mu_{t}, \mu_{t}^{i}\right)$ and $L_{d}^{i}\left(\Theta_{t}, \Theta_{t}^{i}, \mu_{t}, \mu_{t}^{i}\right)$. A stationary equilibrium of the model is an allocation $\left\{Y^{\star}, Y^{i \star}, C^{\star}, C^{i \star}, L_{d}^{\star}, L_{d}^{i \star}, N^{\star}, N^{i \star}\right\}$, a set of prices $\left\{p^{\star}, q^{\star}\right\}$, a set of entry sizes $\left\{B^{\star}, B^{i \star}\right\}$ and a set of distributions $\left\{\mu^{\star}, \mu^{i \star}\right\}$ such that:

- $L_{d}^{\star}\left(\Theta^{\star}, \Theta^{i \star}, \mu^{\star}, \mu^{i \star}\right)=N^{\star}\left(p^{\star}, q^{\star}, \Pi^{\star}, \Pi^{i \star}, T^{\star}\right)$ and $L_{d}^{i \star}\left(\Theta^{i \star}, p^{\star}, \mu^{i \star}\right)=N^{i \star}\left(p^{\star}, q^{\star}, \Pi^{\star}, \Pi^{i \star}, T^{\star}\right)$

- $Y^{\star}\left(\Theta^{\star}, \Theta^{i \star}, \mu^{\star}, \mu^{i \star}\right)=C^{\star}\left(p^{\star}, q^{\star}, \Pi^{\star}, \Pi^{i \star}, T^{\star}\right)$ and $Y^{i^{\star}}\left(\Theta^{i \star}, p^{\star}, \mu^{i \star}\right)=C^{i \star}\left(p^{\star}, q^{\star}, \Pi^{\star}, \Pi^{i \star}, T^{\star}\right)$

- $W^{e}\left(p^{\star}\right) \leq c^{e}$ and $V^{e}\left(q^{\star}, p^{\star}\right) \leq 0$

- $\mu^{\star}=\Psi\left(\Theta^{\star}, \Theta^{i \star}, \mu^{\star}, \mu^{i \star}\right)$ and $\mu^{i \star}=\Psi^{i}\left(\Theta^{\star}, p^{\star}, \mu^{i \star}\right)$

where $\Theta^{\star}=\left\{p^{\star}, B^{\star}\right\}, \Theta^{i \star}=\left\{q^{\star}, B^{i \star}\right\}$ and $\Pi^{\star}, \Pi^{i \star}$ and $T^{\star}$ are all computed according to the equilibrium values. The first two relationships state that, respectively, labor and goods markets must clear in both the informal and the legal sector. The third line states the free entry conditions: providing the assumption of an unlimited supply of potential entrants, in equilibrium the value of entry must be at most equal to the cost of entry, with equality if entry is positive. The last two conditions state that the economy is in a stationary equilibrium, with the distribution over the state reproducing itself every period at the equilibrium values. In appendix, I prove the existence of a model equilibrium under mild regularity (mostly technical) conditions.

Note that the model can exhibit different types of equilibria. In particular, there can be equilibria with entry and exit in both sectors and equilibria without. In addition, an equilibrium can involve entry and exit in both sectors and a measure of firms switching from the informal to the legal sector, but it can as well involve no switch. It is also possible to have mixed situations with, for instance, positive entry in the informal sector, switching and positive exit in the legal sector, but without entry in the legal sector and without exit in the informal. In what follows, I will focus on the interesting case of an equilibrium with entry and exit in both 
sectors and switch. I provide a set of sufficient conditions for the existence of such an equilibrium in appendix. Intuitively, given the structure of the model, there will always be entry and exit in equilibrium in both sectors as long as the demand for both goods is well defined. A sufficient condition is: bounded prices, $\psi \neq 0$ and $\psi \neq 1$. If the price is not bounded in one market, then the demand can possibly be zero and, if demand is zero, there will be no firm willing to produce. Similarly, in case $\psi=0$ or $\psi=1$, the consumers will not demand the good in one of the two markets and no firm will be willing to produce. In addition, the market equilibrium involves switching if the equilibrium price in the legal market is sufficiently higher than the illegal, so that the most productive informal firms will find it profitable to switch. How much higher it should be depends, among others, on the consumer preferences for the legal versus illegal good, on the technological shock and on the fixed and variable costs. For the baseline model parametrization, but also along all the robustness checks that I perform, this condition is always satisfied and the equilibria always involve switching.

\section{Parameters and Calibration}

Since the model cannot be solved analytically, I proceed to a numerical solution. The goal of the analysis is to evaluate numerically the effect of different costs of the legal system on the size and composition of the informal economy. Therefore, in order to isolate these effects from other confounding factors, I fix all the other dimensions of the economy along the numerical exercises. The problem is how to choose the benchmark values of the parameters and calibration targets. I choose to target the benchmark simulation to the US economy, largely for data availability reasons. The drawback of this strategy, however, is that I'm choosing a developed country to parameterize a model of the informal economy, which is arguably a more widespread phenomenon in developing countries. To validate my strategy, I discuss two different sets of results: first, I show (in section 7) that the cross country measure of the informal economy that I obtain with this strategy is reasonable. Second, I propose (in section 8) a detailed discussion of the robustness of the numerical results, including the possibility of a calibration to an economy with a bigger informal sector.

The strategy that I use is to fix as many parameters as possible using outside information and then to calibrate the remaining ones to match firm level statistics from the Census of Manufacturers (similarly to HR). For the parameters for which I don't have hard evidence, I simply check the robustness to a wide range of alternatives. The goal of the calibration is to have a characterization of the legal sector that is in line with the empirical evidence. Since I focus on the stationary equilibrium of the model, I consider just one wave of the census.

According to the time span of the census, I set the time period in my model to 5 years. The discount rate $\beta$ is fixed at a value that implies, in steady state, an interest rate of $4 \%$ a year. The labor share of income $\alpha$ is set to 0.65 , consistently with the US empirical evidence. To keep the differences across the two sectors at a minimum, I assume equal technologies, fixing $\eta=\alpha$ (I relax this assumption in section 8). The output tax $\tau^{y}$ is $29 \%$ per year, which is the average of the ratio between tax receipts on corporate income and corporate income from 1960 to 2003 in the US (Bureau of Economic Analysis data). The price $p$ is the numeraire.

I set the cost of entry $c^{e}$ to $0.5 \%$ of official GDP ${ }^{5}$, consistently with the evidence reported by Djankov et al. (2002) for the US (see infra). I also set the firing costs $\phi$ at 0 consistently with the lower bound measure in Botero et al. (2004) (see infra; a different parametrization with the upper bound measure delivered very similar results). I assume that the exogenous technological shock for incumbents follows an autoregressive process:

$$
a_{t}=\rho a_{t-1}+\varepsilon_{t}
$$

5 To set the value of the entry cost as a percentage of GDP, I iterate over the model solution. In particular, I solve the model for different levels of the entry cost $c^{e}$, compute the ratio between $c^{e}$ and the official sector GDP $Y$ and then select the value of $c^{e}$ such that $c^{e} / Y=0.005$. 
where $\varepsilon_{t} \sim$ i.i.d. $N\left(0, \sigma^{2}\right)$. Following HR, I assume that the pdf $v(a)$ for entrants is simply uniform.

The two preference parameters $\psi$ and $z$ map relative price differences into a relative size of the informal economy. Consistently with the calibration strategy, it is important to set them at a value that delivers a reasonable size of the informal economy in the US. Since there is no hard information to set these values, the best approach is to consider the robustness to a wide range of possibilities. It turns out that these two parameters are not crucial for the results that I discuss in the paper, so that the lack of hard information is not a huge issue. From an operational standpoint, in the benchmark model parametrization I set these two parameters at rather arbitrary values that deliver a reasonable relative size of the informal sector, $\psi=0.95$ and $z=0.25$, and I discuss the robustness to many alternatives in section 8 . The remaining preference parameter $H$ is set at 1.9 to deliver a workers' share in the population of $60 \%$.

The monitoring probability $\pi$ affects the productivity differential across sectors and, therefore, the relative price in the informal market. Its real world counterpart is the probability of discovering a business in the informal economy, which should be different from the probability of a tax audit. Since there is no available information about this probability, I adopt a robustness approach again. As for the preference parameters, I found that the auditing probability is not essential for most of the numerical results. Therefore I proceed again choosing a rather arbitrary but reasonable value for the benchmark parametrization, $\pi=0.1$, and discussing the robustness to alternative values in section 8 .

For what concerns the fixed costs $c^{f}$ and $c^{u}$, there are a priori reasons to believe that the fixed cost is higher in the legal sector, for instance because of the cumbersome regulatory environment or the complex tax system. Nevertheless, there are also a priori reasons to believe that the fixed cost is higher in the informal sector, because of the costs of informality previously discussed. Nevertheless, providing that one of the main background assumptions of the analysis is that the legal system is indeed costly, I assume that the fixed cost in the legal sector $c^{f}$ is higher than its illegal counterpart $c^{u}$. To avoid a big asymmetry between the two sectors, I assume that it is just 10\% bigger. This choice is also sensible from an empirical perspective, albeit conservatively. Data from the Informal Survey and from the Micro Survey, implemented by the World Bank (see La Porta and Shleifer 2008), show that informals and legal firms spend the same amount of money on protection and security, but that legal firms spend more to comply with regulations. For practical purposes, this assumption entails placing a linear restriction in the calibration exercise, reducing the dimensionality of the set of parameters to calibrate. Importantly, this cost asymmetry is almost inconsequential for the bulk of the results: even remaining agnostic about the relative magnitude of the two fixed costs, setting them as equal, would result in the same model properties and counterfactual results. My choice of slightly different costs is actually for convenience: it significantly eases the computational burden, making it faster to find an equilibrium with switching informals.

I then calibrate the two, linearly related, fixed costs $c^{f}$ and $c^{u}$, together with the two parameters of the technological shocks $\rho$ and $\sigma$, to reach 3 targets from the census of manufacturers: an exit rate of 40\%, a job turnover rate of $30 \%$ and a coefficient of serial correlation of employment of 0.93 . The resulting parameters value are: $c^{f}=0.03, c^{u}=0.027, \rho=0.82$ and $\sigma=0.11$. Perhaps the persistence of the technological shock might seem high, especially as compared to HR. Nevertheless, it is quite difficult to obtain a plausible exit rate from the model without appealing to persistent technological shocks. Moreover, as shown in section 8, this high persistence does not influence the model results significantly and thus should not be viewed as a limitation of the analysis.

I obtain a stationary equilibrium with a legal sector that behaves coherently with the empirical evidence summarized, among others, by Evans (1987), Davis and Haltiwanger (1988) and Dunne, Roberts and Samuelson (1989). The reason is that I follow the calibration strategy of other papers of industry equilibrium that match the same empirical information. In particular, the size distribution of the legal firms is stochastically increasing in age and the exiting probability is decreasing in firms' age. Also, as in most model of industry dynamics similar to Hopenhayn (1992) and Hopenhayn and Rogerson (193), small firms account for most of the hiring rate, while large firms account for most of the firing. 


\section{Informality as the Doorstep of Legality}

I now show that the characterization of the informal sector implied by the model is consistent with the available survey evidence, as reported by Maloney (2004), La Porta and Shleifer (2008), De Paula and Scheinkman (2008) and Dabla-Norris et al. (2008): small establishments, less productive, exposed to market whims and thus characterized by a high death rate.

Looking at the stationary distributions of the size of legal and informal firms, I find that informal firms are significantly smaller than their legal counterparts, both in terms of output and in terms of employment. Looking at the stationary distributions of productivity, I find that the productivity is also much smaller, on average, in the informal sector. Both model results are in line with the survey evidence from the World Bank's Informal Survey and Micro Survey (La Porta and Shleifer 2008). Consistently with the smaller size and productivity of informal firms, the model also delivers a significantly higher exit rate in the informal sector.

The measure of switching informal firms is small. In the stationary equilibrium of the benchmark model, roughly $30 \%$ of the informals legalize. This implies that, in each period, only $1.5 \%$ of the legal firms were previously informal. This feature of the model is indeed consistent with the survey evidence summarized by LaPorta and Shleifer (2008), who report that, in their sample of developing countries (typically characterized by a higher start-up cost and, therefore, by a bigger number of informal firms), $91.2 \%$ of legal firms started as legal (on average).

A further feature of the stationary equilibrium is that, in the five years' period that I use in the calibration, informal firms that experience favorable productivity shocks legalize, while less productive informals exit. In this respect, the model implies a characterization of the informal sector as a Doorstep of the official: many firms start informally on a small scale, then waiting to become more productive and to grow before legalizing. This pattern is indeed consistent with the survey evidence reported by Maloney (2004), showing that, in Mexico, informal firms tend to become formal with age and size. The model is also consistent with De Paula and Scheinkman (2008) who report that, in Brazil, only bigger and more productive informals find it profitable to legalize. A further implication of the model is that informal firms legalize quickly, in line with the survey evidence reported by LaPorta and Shleifer (2008). In their sample, 2/3 of the firms legalize within 5 years and $80 \%$ within 10 years. These numbers are indeed what the model would deliver as an equilibrium if parameterized with the start-up and operational costs of the developing countries where the surveys were conducted (see infra).

The Doorstep theory is akin to the idea of entrepreneurship and selection by Jovanovic (1982). In a nutshell, potential entrepreneurs can learn about their productivity and the market conditions only if they actually start a business. If they are not productive, they are forced to drop out of the market. My model adds to this theory that if the costs to start a business legally are high, then the entrepreneurs choose to go through the learning stage in the informal sector. Therefore the Doorstep theory explains the lower productivity of the informal firms as a consequence of the dynamics of new start-ups in the presence of entry barriers, not simply as a consequence of their lower productivity.

\section{Numerical Analysis}

The quantitative experiment entails plugging in the calibrated model the observed costs of the legal system, to analyze the implied cross country differences in the size of the informal economy. I interpret this differences as the one that would prevail if the only cross country heterogeneity entailed the start-up costs, the labor market regulations and the tax rate, holding fixed all the other characteristics of the economy. Two main results stand out. First, the cross country variability in the extent of labor market regulations and taxation account only for a small fraction of the cross country variability of the size of the informal economy, while the start-up costs account for most of it. Second, the start-up costs account for a greater fraction of the informal economy in the countries characterized by bigger informal sectors. 


\subsection{Data}

I consider two measures of the start-up costs from Djankov et al. (2002): the first (ce) simply takes into account "All identifiable official expenses" to get the authorizations required to start a business legally, thus excluding the eventual bribes. The second (cetime) adds to the first a "Monetized value of the entrepreneurs' time", accounting also for the length of the bureaucratic procedures. Both variables are measured as a percentage of the GDP per capita of the country. A third measure of the start-up cost (wbce) is from the World Bank Development Indicators and it refers to the total cost to start a business as a percentage of GNP per capita.

I take two measures of firing cost from Botero et al. (2004). The first ( $\mathrm{sev}$ ) is the weeks of "Legally mandated severance payment requirements in case of redundancy dismissal". The second (sevadv) adds to the first the "Legally mandated advance notice requirements", assuming that the wage paid during the notice period is an additional monetary cost for a firm willing to lay-off a redundant worker. The third measure of firing costs ( wbsev) is reported by the World Bank Development Indicators. The tax pressure (tax) is from the World Bank Development Indicators and it quantifies the tax rate on income profits and capital gains.

I construct two data sets: the first (Mixed Sample) with the data from Djankov et al. (2002) and from Botero et al. (2004), together with the tax rates from the WB; the second (WB Sample) using only data from the WB, averaged over the period 2002-2006. In both cases, the data are collected for the biggest sample of countries for which there is information on all variables, which means 78 countries in the first case and 90 in the second (note that not all the countries in the Mixed sample are included in the WB sample). These numbers do not include the countries with extremely high values of the cost of entry in excess of $150 \%$ of the GDP per capita (not taking into account the opportunity cost of time), that I excluded from the analysis.

Overall, there is evidence of a significant cross sectional variability of the three costs, which excludes the possibility that the numerical results are driven by a higher cross sectional variability of the start-up costs. In particular, the coefficients of variation of the start-up costs in the mixed samples are equal to, respectively, $63.9 \%$ (ce) and $80.3 \%$ (cetime). The coefficients of variation of the firing cost variables are equal to $69.7 \%$ (sev) and $86.3 \%$ (sevadv) and the coefficient of variation of tax rates is equal to $59.9 \%$. As far as the WB sample is concerned, the coefficients are 54.5\% (wbce), 77\% (wbsev) and 91.8\% (wbtax).

\subsection{Cost Decomposition}

The model implies that the cross country differentials in the start-up costs account, on average, for $74.9 \%$ of the cross country variability of the size of the informal economy. Labor market regulations and tax rates account for, respectively, $10.9 \%$ and $14.2 \%$. Using the alternative data from the WB, the fractions become, $63.9 \%, 5.2 \%$ and $30.9 \%$. The first row of Table 1 summarizes the results and includes also the median values and the standard deviations of the individual contributions. The procedure behind the decomposition is the following. First, I feed in the model the three costs of the legal system to obtain the simulated size of the informal economy. Then I exclude one of the costs and obtain a different measure of the informal economy. I interpret the difference between these two measures as the contribution of the excluded cost to the simulated informal economy. I obtain the relative contribution of all costs simply dividing the absolute value of the individual contributions by the sum of the absolute values of the contributions.

Further decomposing the contributions by quartiles of the informal economy reveals an additional result: the start-up costs are more important in countries with bigger informal sectors. The second part of Table 1 reports the average and median contributions of the costs in the four quartiles of the distribution of the informal economy, together with the standard deviations of the contributions. The contribution of the start-up cost to the informal sector is higher at the top quartile and the variability of its contribution lower. In greater detail, the start-up cost, in the mixed sample, accounts for $61 \%$ of the informal economy in the bottom quartile of the distribution but for $80 \%$ in the top quartile. Even more striking is the difference in the WB sample, with just $40 \%$ in the lower quartile and $80 \%$ in the top. Also the standard deviation drops from around $27 \%$ in the bottom quartile to $4 \%$ in the top one. The specular result is that the contribution of the tax rate is much 
smaller in the top quartile, with a value that drops from the $56 \%$ to the $9 \%$ in the WB sample and from $32 \%$ to $7 \%$ in the mixed sample.

\subsection{Regressions with the Simulated Informal Economy}

A further way to assess the relative importance of the costs is running a regression of the simulated size on the costs used to simulate it. The model is the following:

$$
y_{j}^{i}=\gamma_{1}+\gamma_{2} c_{j}^{e}+\gamma_{3} \phi_{j}+\gamma_{4} \tau_{j}^{y}+\epsilon_{j}
$$

where $y_{j}^{i}=Y_{j}^{i} / Y_{j}$ is the ratio of informal to legal output, $c_{j}^{e}$ the cost of entry in the legal sector, $\phi_{j}$ the firing cost, $\tau_{j}^{y}$ the tax rate on output and $\epsilon_{j}$ an error term that depends on computational noise only. As a benchmark case, I consider the upper bound measures of both $c^{e}$ and $\phi$ in the mixed sample. The result is $\gamma_{2}=0.325$ and significant at the $1 \%$ level, $\gamma_{3}=0.021$ and not significant and $\gamma_{4}=0.154$ and significant at the $1 \%$ level, with an $R^{2}$ very close to 1 as expected. The first important evidence is that labor market regulation does not explain at all the size of the informal economy. The second is that the contribution of the tax rate, while statistically significant, is much smaller than the contribution of the start-up cost. In fact, an increase of one standard deviation in the tax rate, equal to $13 \%$, predicts a $2 \%$ increase of $y^{i}$. The difference between the third and the first quartile of the tax rate, equal to $18 \%$, predicts a $2.7 \%$ increase. Conversely, a one standard deviation increase of $c^{e}$, equal to $27 \%$, predicts an $8.7 \%$ increase of $y^{i}$, while the difference between the third and the first quartile, equal to $30 \%$, a $9.75 \%$ increase. The results obtained with the lower bound measures of

Table 1: Percentage contribution of the costs of the legal system to the simulated size of the informal economy

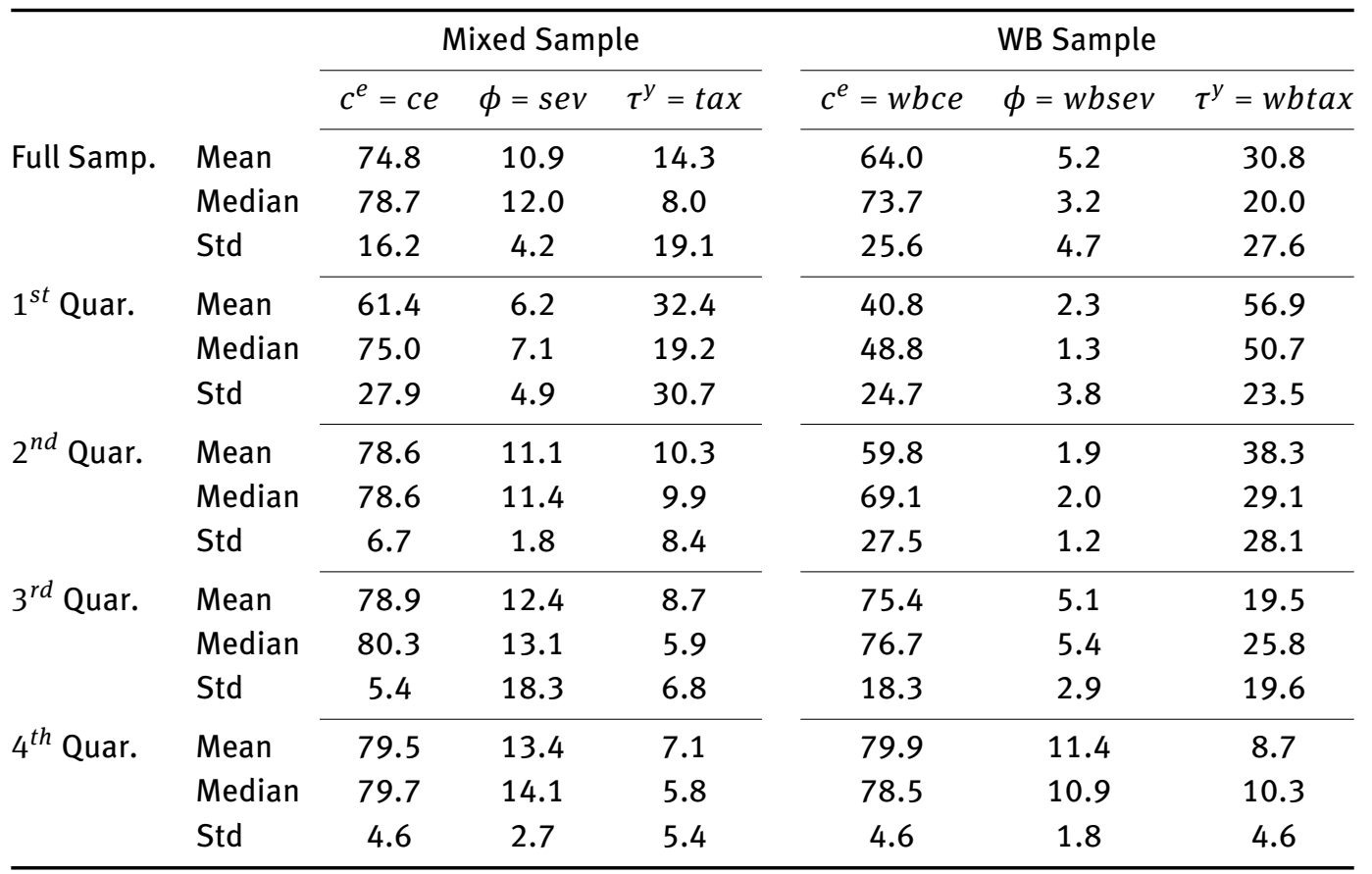

Notes: Summary statistics relative to the distribution of countries simulated from the model using data on the costs of the legal sector and keeping the parametrization at its benchmark level. Mixed Sample: $c^{e}=c e$ is the start-up cost as a percentage of GDP per capita computed by Djankov et al. (2002). $\phi=s e v$ is the per period wage equivalent of the weeks of severance payments reported by Botero et al. (2004). $\tau^{y}=\operatorname{tax}$ is the tax rate on income, profits and capital gains from the World Bank Development Indicators (WBDI). 78 countries simulated. WB Sample: all data are from the WBDI and averages over the period 2002-2006. $c^{e}=w b c e$ is the start-up cost as a percentage of GNI per capita. $\phi=w b s e v$ is the per period wage equivalent of the weeks of severance payments and $\tau^{y}=w b t a x$ is the tax rate on income, profits and capital gains. 90 countries simulated. The Quartiles refer to the distribution of the relative size of the informal economy implied by the model. 
the costs, or with combinations of lower and upper bound measures, are indeed very similar, as they are the results obtained with the WB sample.

\subsection{Comparative Statics}

I now analyze the effects of the costs on the model equilibrium in greater detail. The results are reported in Table 2.

As already stressed by Hopenhayn (1992) and, although in the context of a different model, by Blanchard and Giavazzi (2003), the start-up cost protects incumbent legal firms, reducing both the rate of entry and the rate of exit, lowering output and raising its price ${ }^{6}$. Overall, a higher start-up cost increases the profits of legal firms and their average size, thus creating rents for big incumbent firms, isolating them from the threat of potential competition. Nevertheless, the profits of small legal businesses are still very close to zero even after the introduction of entry barriers: the real beneficiaries of the entry regulations are the bigger and more productive incumbents, whose profits grow faster than the profits of small incumbents. Importantly, the cost of entry does not protect incumbent firms from the competition of informals that legalize ${ }^{7}$. Namely, a higher start-up cost, by raising the profitability of the legal firms, and in particular of the bigger and most productive legal establishments, delivers a contemporaneous increase of both the costs and the benefits of producing legally, leaving the terms of the trade-off barely affected. As a consequence, the switching rate does not change significantly. This result implies, among other things, that the benefit of entry barriers for incumbents are overstated without a careful analysis of the effects on the informal sector.

Together with the lower entry in the legal sector, a higher start-up cost delivers also more entry in the informal sector. Entrants in the legal sector are such that $W^{e}\left(p_{t}\right)-c^{e}>V^{e}\left(q_{t}, p_{t}\right)$. Since the value of entry in the legal sector is not much affected by $c^{e}$, because the profits of smaller firms respond much less than the profits of bigger firms to the introduction of entry barriers, an increase in $c^{e}$ displaces part of the new entrants in the informal sector ${ }^{8}$. The cost of entry in the legal sector determines an increase in the relative size of the informal economy, through an increased numerator and a decreased denominator. Figure 1 shows the changes in the distributions of firms that follow the increase of the start-up costs: the size distribution of legal firms is increasing, with a clear increased measure of bigger firms. The distribution of informal firms shows a higher concentration in the lower tail, substantially driven by the increased informal entry.

Increased firing costs, by reducing the flexibility of legal firms, induce lower profits in the legal sector and a decreased present value of legal firms 9 . This, in turn, increases the relative price in the legal market, lowering the switching rate. The average size and the average productivity of the legal firms are lower. In the informal sector, conversely, the average productivity is higher, since there is a lower mass of informals that switch. The economy is also characterized by a more stable labor force: hiring and firing rates are both lower, as is the job turnover rate, while the serial correlation in employment is higher. In line with HR, there is also a reduction of aggregate employment.

An increased output tax induces a decrease in legal output that, by itself, drives an increase in the relative size of the informal economy. The average size and the average productivity of the legal firms decline and the legal price increases. The higher taxes induce also a smaller expected benefit of legalization, which compensates the increased price, without any significative effect on the switching rate.

6 Bertrand and Kramarz (2002) found also empirical evidence that, in a sample of French manufacturing establishments, more strict entry regulations explain lower sales, lower rates of employment, higher concentration (and so size) and higher prices.

7 Estrin and Mickiewicz (2012) discuss extensively the relationship between entry by new entrepreneurs and the size of the informal economy.

8 This property of the model is consistent with the empirical results by Klapper, Laeven and Rajan (2006), that find both a smaller rate of entry and a higher size of entry in the countries characterized by higher start-up costs.

9 This result is in line with the empirical evidence summarized by Almeida and Carneiro (2005). They report that, in Brazil, increasing the enforcement of labor market regulations determines not only with a decrease of the informal labor force, but also a decreased value added per worker and sales per worker. 


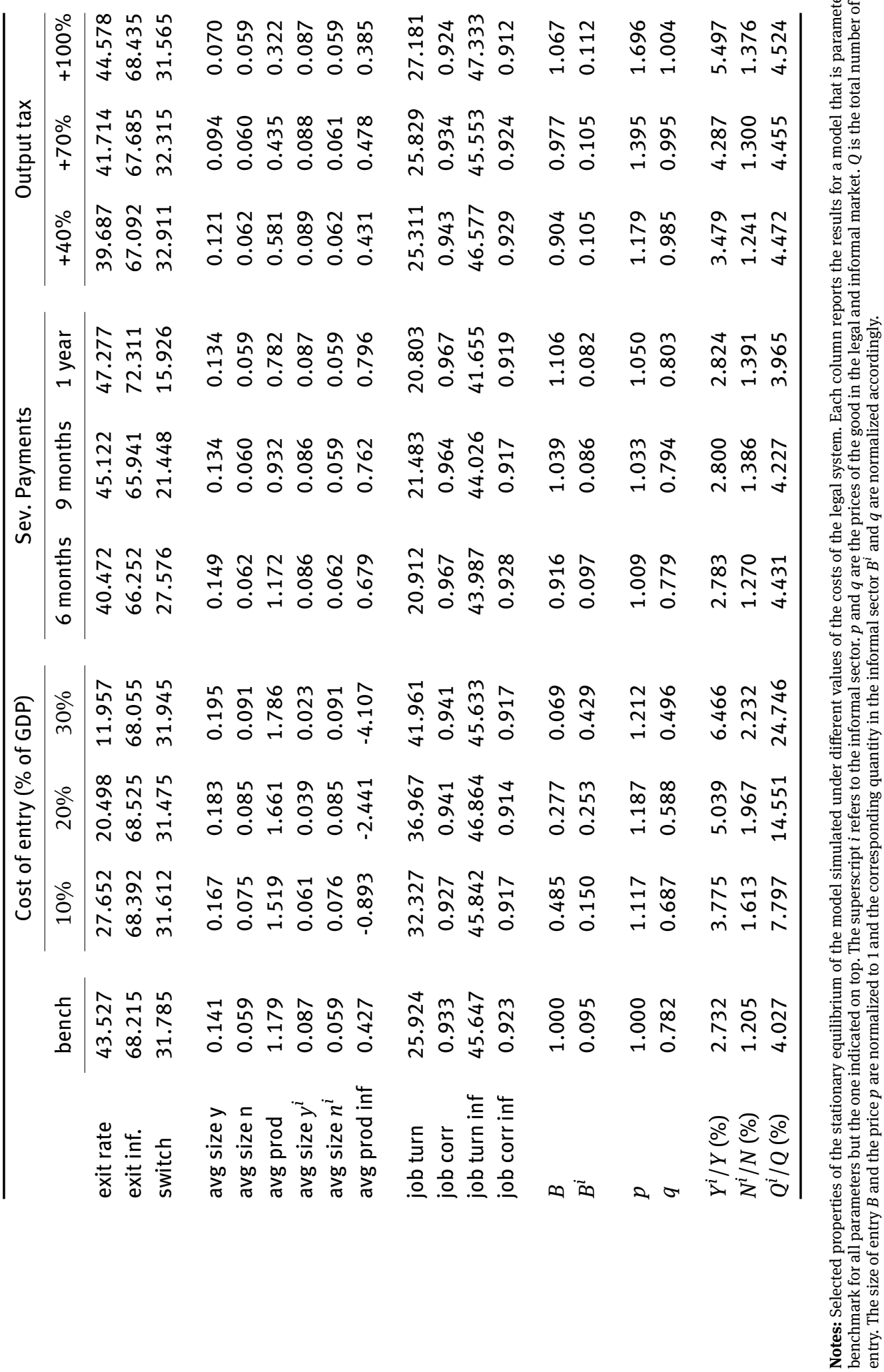



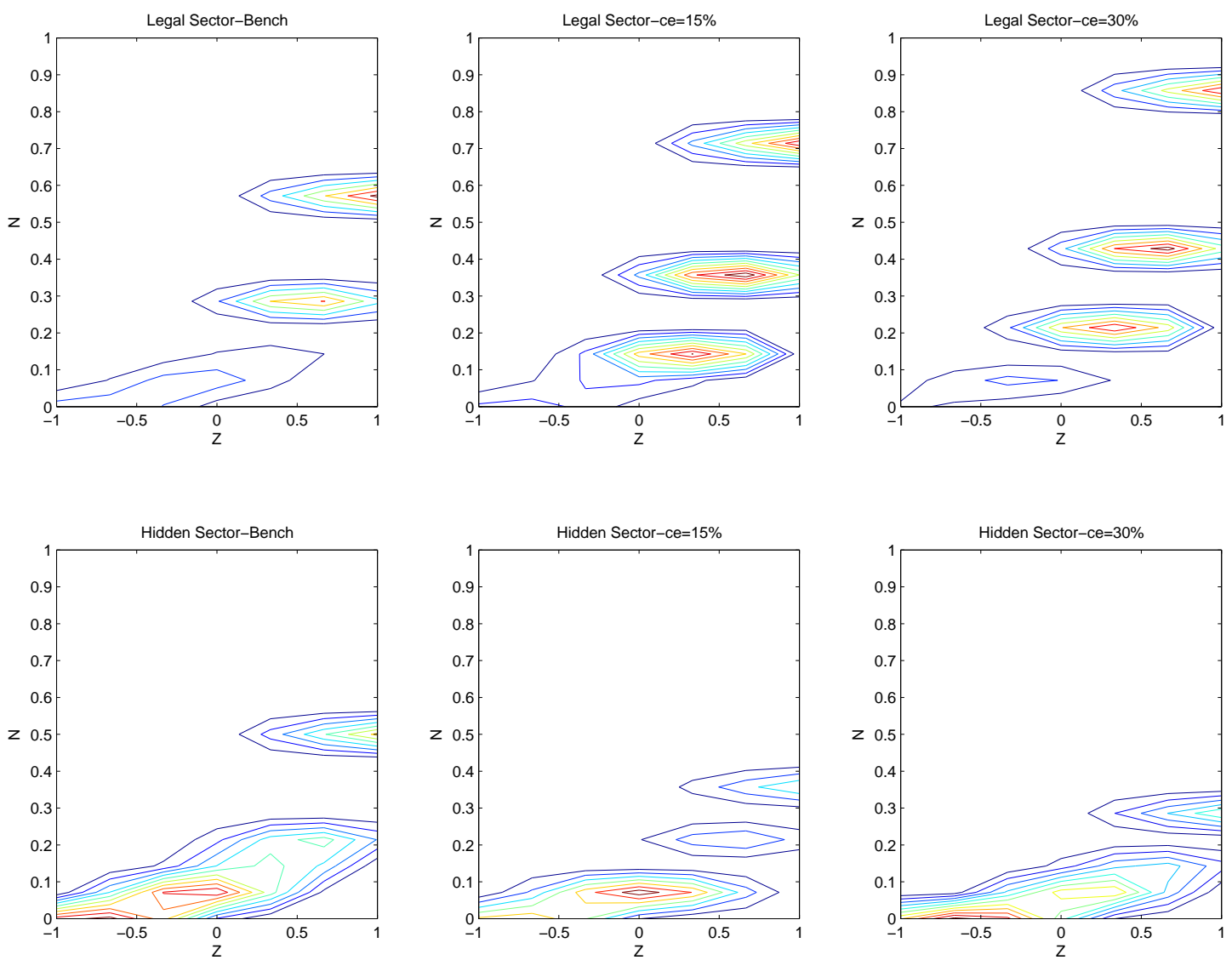

Figure 1: Size Distribution-Cost of Entry

Notes: Contour plot of the size distribution of legal firms (upper panel) and informal firms (lower panel) for different values of the start-up cost. Bench refers to the benchmark zero value of the start-up cost. $N$ is the normalized level of employment. $Z$ is the normalized value of the technology.

\section{Empirical Validation}

In this section, I propose an empirical test to validate the model. In particular, I test its ability to deliver empirically plausible measures of the size of the informal economy. In particular, I compare the model based measures of the informal economy to the available empirical estimates. Indeed it is necessary to be extremely careful when using these estimates as benchmarks, since all the estimation methods hinge on strong empirical assumptions. Nevertheless, it is also the case that these estimation methods are based on indicators that are extremely likely to be correlated with the extent of informal activities. In other words, it is safe to assume that the estimates provide an idea of the cross country variability of the informal economy consistent with the cross country variability of its indicators.

I consider 4 different estimates of the size of the informal economy. 3 measures are based on indirect estimation methods: the Aggregate Electricity Consumption method (Johnson et al. 1997 and 1998), the Household Electricity Consumption method (Lacko' 1999) and Schneider's (DY)MIMIC method (Schneider 2005), which is itself a combination of the Loayza's MIMIC method (Loayza 1996, Giles 1999) and of the Currency Demand method (Tanzi 1983). A fourth measure is the index of informal activities from the 2006/2007 World Competitiveness Report survey, as re-scaled by LaPorta and Shleifer (2008). 

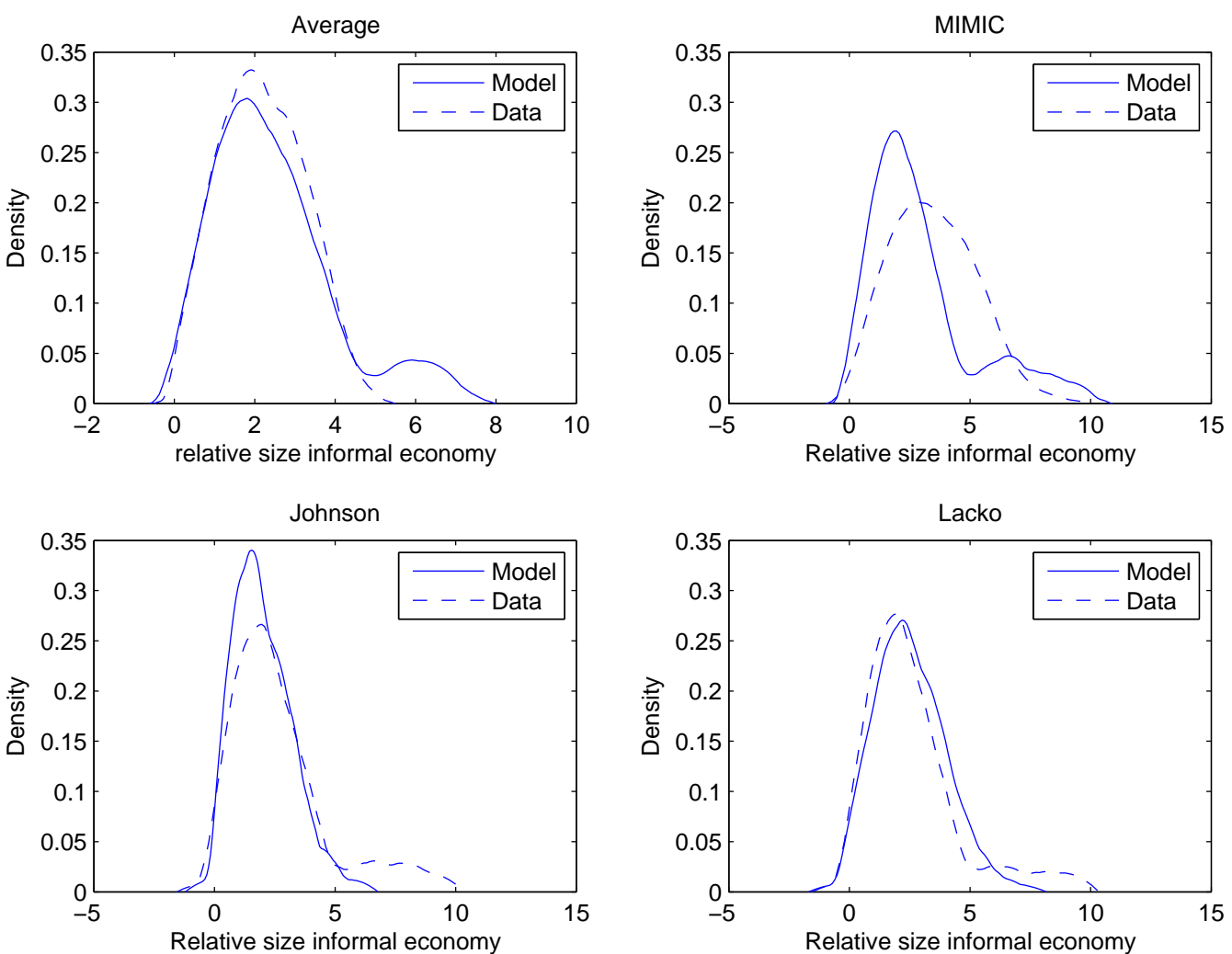

Figure 2: Relative Size of the Informal Economy

Notes: Empirical distribution of the estimated and simulated size of the informal economy relative to the size in the US. Upper right panel: Schneider's MIMIC estimates (Schneider 2005). Lower right panel: Lacko's household electricity consumption estimates (Lacko' (1999)). Lower left panel: Johnson's electricity consumption estimates (Johnson et al. (1997) and (1998)). Upper left panel: average estimates over the previous method and over WEF survey measures as rescaled by LaPorta and Shleifer (2008). All the estimates are obtained with an Epanechnikov kernel. The number of observations varies.

Importantly, the correct interpretation of the model measures is of a relative size of the informal economy that would prevail in a country exactly similar to the US except for the level of taxes, the entry cost and the labor market regulations. Therefore, in this exercise I consider the estimated size of the informal economy relative to the size in the US.

Figure 2 plots the cross sectional distribution of the relative measure of the informal economy delivered by the model together with the cross sectional distribution delivered by the empirical estimation methods. The model measures are obtained feeding in the model the upper bound measure of labor market regulation $(\operatorname{sevadv})$ and the upper bound measure of the start-up cost (cetime), together with the measure of tax pressure ( $\operatorname{tax}$ ). As the plot shows, the model provides an empirically reasonable measure of the informal economy. The most interesting result is perhaps the similarity with the average empirical estimates, since they smooth out the extreme values delivered by some estimation methods. The results obtained feeding in the model the lower bound measures of the costs, or combinations of lower bound and upper bound measures, are indeed very similar. The WB cost measures also deliver similar results.

Another way to look at this result is to compute the correlation between the model based relative estimates and the empirical estimates. Table 3 reports these correlations, both by estimation methods (including the average, minimum and maximum empirical estimates) and by stage of economic development. The table refers again to the model based measures obtained with the upper bound measures of the costs. Overall the correlation is higher for OECD countries and for the Electricity Consumption methods. This last evidence is particularly important, since these estimates are not constructed using any of the information that I use to 
Table 3: Size of the Informal Economy, Correlations Model-Data

\begin{tabular}{lccccccc}
\hline & Avg & Johnson & Lacko & MIMIC & WEF & Min & Max \\
\cline { 2 - 8 } All Sample & $\begin{array}{c}0.521 \\
(70)\end{array}$ & $\begin{array}{c}0.576 \\
(51)\end{array}$ & $\begin{array}{c}0.621 \\
(51)\end{array}$ & $\begin{array}{c}0.383 \\
(70)\end{array}$ & $\begin{array}{c}0.502 \\
(68)\end{array}$ & $\begin{array}{c}0.533 \\
(70)\end{array}$ & $\begin{array}{c}0.441 \\
(70)\end{array}$ \\
\cline { 2 - 7 } OECD & $\begin{array}{c}0.618 \\
(23)\end{array}$ & $\begin{array}{c}0.743 \\
(21)\end{array}$ & $\begin{array}{c}0.652 \\
(21)\end{array}$ & $\begin{array}{c}0.601 \\
(23)\end{array}$ & $\begin{array}{c}0.611 \\
(23)\end{array}$ & $\begin{array}{c}0.594 \\
(23)\end{array}$ & $\begin{array}{c}0.589 \\
(23)\end{array}$ \\
\cline { 2 - 8 } Transition & $\begin{array}{c}0.235 \\
(16)\end{array}$ & $\begin{array}{c}0.364 \\
(13)\end{array}$ & $\begin{array}{c}0.275 \\
(15)\end{array}$ & $\begin{array}{c}0.175 \\
(16)\end{array}$ & $\begin{array}{c}0.135 \\
(16)\end{array}$ & $\begin{array}{c}0.175 \\
(16)\end{array}$ & $\begin{array}{c}0.225 \\
(16)\end{array}$ \\
\cline { 2 - 8 } Developing & $\begin{array}{c}0.410 \\
(31)\end{array}$ & $\begin{array}{c}0.494 \\
(17)\end{array}$ & $\begin{array}{c}0.685 \\
(15)\end{array}$ & $\begin{array}{c}0.232 \\
(31)\end{array}$ & $\begin{array}{c}0.397 \\
(29)\end{array}$ & $\begin{array}{c}0.431 \\
(31)\end{array}$ & $\begin{array}{c}0.283 \\
(31)\end{array}$ \\
\hline
\end{tabular}

Notes: Correlations between the estimated size of the informal economy and the size of the informal economy delivered by the simulated model with the upper bound measure of labor market regulation (sevadv), the upper bound measure of the start-up cost (cetime) and the measure of tax pressure (tax). Johnson are the estimates obtained with the electricity consumption method (Johnson et al. (1997) and (1998)), Lacko' the estimates obtained with the Household Electricity Consumption method (Lacko' (1999)), MIMIC the estimates obtained by Schneider (2005) with the Multiple Indicators Multiple Causes method and WEF the survey based measure of the informal economy rescaled by LaPorta and Shleifer (2008). Avg is the average estimate, Min is the smallest estimate and Max the biggest. The number of observations is in brackets.

construct the model. The correlation values for the entire sample range from the $38 \%$ of the MIMIC measures to the $62 \%$ of the Lacko' Electricity Consumption method. The low correlation with the MIMIC measures, in turn, depends mostly on the small correlation with the estimates for transition and developing countries.

\section{Sensitivity Analysis}

In this section, I analyze the robustness of the results to alternative assumptions and parameterizations.

The first exercise entails relaxing the assumption of equal technologies in the two sectors. DeSoto (1989), Lemieux et al. (1994) and Koreskova (2006), among others, claim that informals lack in organization and that they are unable to reach economies of scale, since they must remain small to avoid detection. Therefore, it is plausible that the same labor force is used less efficiently in the informal sector with, in the model, $\eta<\alpha$. In this different scenario, for a value of $\eta$ that is between $10 \%$ and $20 \%$ lower than $\alpha$, the model equilibrium is characterized by a non-zero measure of (highly productive) informal firms that choose to stay informal. As a direct consequence, the average size of informal firms is higher, and so is their average productivity. Also the relative size of the informal economy is bigger, both in terms of output (on average by $40 \%$ in the cross section) and labor input. There are two new features of the model that significantly affect the comparative statics results. First, the introduction of entry barriers now implies an increase of the switching rate: the benefits of legalization (the profits available in the legal sector) grow faster than the costs for a big pool of (relatively) high productive informals. However, the entry rate in the illegal sector also grows faster than in the benchmark model parametrization. The reason is the higher anticipated profits from a future switch to the legal sector, which happens in case of a sufficiently high productivity shock. Overall, the average size of the hidden economy grows. Second, the introduction of firing costs does not trigger a significative increase of the measure of firms that remain informal, with an overall lower growth of the informal sector. The reason is that many of those firms now remain informal even in case of a zero firing cost. In conclusion, assuming a technological asymmetry between the legal and the informal sector results in a similar effect of the entry cost but in a lower effect of labor market regulations, confirming the main results of the paper. 
Changing the auditing probability $\pi$ impacts the productivity differential across sectors. In the benchmark parametrization, the output tax rate is higher than the auditing probability, thus determining an advantage for informals. Providing that this might seem an unreasonable scenario, I solved the model for a higher probability of auditing, in particular equal to 2 times its estimated value for the US. The results are not affected. Specifically, the higher value of the probability delivers a lower relative size of the informal sector, determined both by the lower effective productivity and by the higher price in the informal market. Despite this difference, all the comparative statics results relative to $c^{e}$ and $\phi$ are unaffected. The effect of taxes, on the other hand, is substantially lower. This is because the same tax rate increase delivers now a smaller productivity differential and thus a lower decrease of the legal production.

The model delivers a ratio of informal to formal consumption (or output) that depends on the relative price and upon the preference parameters $\psi$ and $z$. Specifically:

$$
\frac{C_{t}^{i}}{C_{t}}=\left(\frac{1-\psi}{\psi} \frac{p_{t}}{q_{t}}\right)^{\frac{1}{1-z}}
$$

Essentially consumers buy goods from the informal market because it is customary. The custom (or habit) is determined by the parameter $\psi$, with a lower value associated with societies where informal goods or services are widespread and easily accessible. Depending on the relative price ${ }^{10}$ and the elasticity of substitution $z$, the fraction of informal goods purchased can be bigger or smaller, but, as long as $\psi \neq 1$, it will never be equal to zero.

The question, then, is if the model results are robust to different values of $z$ and $\psi$. A higher $z$ delivers a higher relative size of the informal economy along all exercises, magnifying the effect of the same relative price change. Viceversa, a lower value of $z$ delivers a muted effect with respect to the benchmark parametrization. The ranking of the costs according to their effect on the informal economy should be preserved, unless the benchmark value of $z$ was extremely high, which is not the case. Quantitatively speaking, doubling $z$ would result in an effect of $c^{e}$ that is roughly 2.5 times bigger than in the benchmark model, and in effect of $\phi$ slightly less than two times more. Conversely, halving $z$ results in a 30\% lower effect of $c^{e}$ and a 20\% lower effect of $\phi$. Similar considerations apply for the tax rate $\tau^{y}$.

Similarly, the benchmark model parametrization implies an extremely low value of the relative size of the informal economy, consistently with the empirical evidence for the US, which is the consequence of a very small $\psi$. Nevertheless, this value does not influence the comparative statics results, mainly because $\psi$ is just a scale parameter, that can at most determine small changes in the level of entry. To test for robustness, I considered an hypothetic alternative country which is exactly equal to the US except for the relative size of the informal economy, which I set to $22 \%$. I obtained this value fixing $\psi$ at 0.8 and keeping all the other parameters constant. The results are very similar to the benchmark US calibration. The only difference is a slightly lower impact of $c^{e}$, delivered by a slower increase of the entry rate in the informal sector.

Another potential source of concern regarding the results is the high persistency of the technology shock. In fact it is possible that the hiring rate is not significantly affected by the firing cost simply because the firms anticipate that the job created will last for longer, highly discounting the future dismissal cost. Therefore the small impact of $\phi$ on the model equilibrium could be just a byproduct of the calibration. I did the same comparative statics exercise for a much smaller value of the shock persistency, 0.62 (the value used by HR and in other, partially different, models of industry dynamics like Hennessy and Whited 2005) without any major change. In particular, I found a slightly weaker effect of $c^{e}$, but the analysis still highlights it as the most important cost in relative terms. This weaker effect of $c^{e}$ is a consequence of the lower expected continuation value of legal firms, that implies a lower switching rate and a higher exit rate in both sectors. In this scenario, the insulating effect of the entry barrier, by raising the value of the legal firms, determines also an increase of the switching rate (with the benefits of switching raising proportionately more than the costs) and thus

10 Notice that the prices also play another important role in the consumer decisions: an excessive price in the legal market can motivate households to search for a better price in the informal one. The simplified framework of the model does not capture this search effect. 
a further increase of the aggregate output. In addition, the lower shock persistence delivers also a lower continuation value for the informals, which induces a lower entry in the informal sector for each value of the start-up cost. This effect limits the expansion on the informal output that follows the introduction of entry barriers. In a nutshell, less persistent technology shocks make it also less attractive to start a new informal business. Importantly, with this level of shock persistence, it is almost impossible to calibrate the model to have an exit rate in the legal sector below $55 \%$. In fact, the reported results are delivered for a benchmark exit rate of that implausibly high magnitude.

\section{Conclusion}

Imposing a high and, sometimes, disproportionate cost to legally start a business discourages potential entrepreneurs, making it more attractive to start informally. The contribution of this work shows that these start-up costs robustly explain the cross country variability of the size of the informal economy and, perhaps more importantly, shows it with a structural dynamic model, that allows for a clear interpretation of the effects. The model itself is also shown to be empirically plausible, since it delivers a cross section of the informal economy that is very similar to all the available empirical estimates. In addition, the characteristics of the informal sector in the model are also shown to be consistent with the available survey evidence.

The importance of barriers to entry to explain the informal economy is an alternative to the conclusion by La Porta and Shleifer (2008). They interpret the smaller productivity of the informal firms as evidence against the Romantic theory of the informal sector, according to which the informal entrepreneurs are dynamic and productive, but somehow trapped in the informal sector by cumbersome regulations. I showed that the evidence of a lower productivity of the informals is also consistent with a Doorstep theory of informality, which exploits the dynamics of new start-ups in the presence of entry regulations. Nevertheless, with my model I cannot dismiss the theory by La Porta and Shleifer (2008).

It is important to stress that the conclusion of the work must not be confused with a simplistic endorsement of the abolition of any form of product market regulation. In fact the paper argues against unnecessary bottlenecks in the bureaucratic process, whose only scope is rent seeking. It certainly does not argue against screening procedures that assess the quality of new entrants, that are likely to be welfare enhancing. In a sense, it is not desirable to eliminate the incentives for producing in the informal sector, exactly because this would translate into a potentially harmful product market deregulation. Making a parallel with the analysis of Acemoglu and Verdier (2000), there is a trade-off between market failures and the informal economy, and tolerating a moderate size of the informal economy can be less dangerous that allowing an indiscriminate entry in the legal sector. The problems arise if the start-up costs reach extremely high values, or if the greatest part of them is accounted for by rent seeking behaviors (as it is the case, according to Djankov et al. 2002): then the economy can end up with a big number of entrepreneurs that, operating in the informal economy, do not comply with the welfare improving regulations, fostering the emergence of the problems that the regulations are supposed to solve. In other words, reducing unnecessary entry barriers is a way to enforce a welfare enhancing regulation of the economy, which is otherwise threatened by the option to produce informally.

A potential drawback of the paper is that the structural modeling of the benefits of the legal sector is severely limited. Legal firms have access to courts, which, more or less perfectly, can enforce contracts. Legal firms can also collateralize their capital to obtain loans, or they can just use the financial market to raise new capital. They can also advertise the product, having access to markets beyond the local areas. In the paper, I modeled these features with a fixed cost of informality, which I then calibrated. But this strategy does not allow for a good evaluation of the importance of these factors. The reason why I abstract from a structural modeling of these costs is to have a tractable framework and an easily interpretable comparative statics. However, although these exclusions are important from a theoretical standpoint, their quantitative importance is likely to be small. The access to external financing, for instance, is almost precluded also to small legal firms (Beck and Demirguc-Kunt 2006; Dabla Norris, Gradstein and Inchauste 2008). Therefore, since new start-ups are small, it is not among the reasons for which entrepreneurs choose to start legally. 
The access to courts is also unlikely to be an important advantage of legal firms in the countries where the judicial trials are long and unpredictable (Djankov et al. 2003). The possibility of advertisement to reach more markets is also typical of large, expanding firms, while small businesses typically rely on word of mouth and personal reputation, which are also available to informals. These considerations suggest that the results of the analysis are strong, despite the stylized framework.

A conceptual limitation of the paper is that it explains the informal economy as an optimal exit response (Hirschman 1970) to an oppressive state, without distinguishing this theory from an alternative based on ethical considerations and network effects. To be specific, there are some national or cultural contexts where informality is tolerated as an almost legitimate way of doing business and, therefore, where the costs for informals are very small. This social acceptance can also foster network effects, since being informal among other informal firms is much less costly ${ }^{11}$. In other words, it can be the absence of a law abiding population and the lack of a strong moral commitment to be the real determinant of a large informal sector, not rentseeking governments and bureaucracies. One possible defense of my analysis is that the social acceptance of informality can develop as a consequence of an oppressive state, so that the prior is indeed the cost of the legal system. Namely, the exit response triggered by the high costs of the legal system could foster a social acceptance of the response itself, that neutralizes the social stigma of informality.

A further limitation of the paper is that it only proposes an analysis of the cross sectional determinants of the informal economy. It does provide any answer to the extremely interesting question of what drives the growth or decline of the informal economy through time. Actually, the start-up cost is an unlikely candidate for such an explanation, since legal systems are typically very resilient to change. Furthermore, since I consider the stationary equilibrium of a dynamic model, I cannot use my numerical strategy to study time series variability at short horizons.

Acknowledgement: I would like to thank the editor, two anonymous referees, Francois Gourio, Luigi Guiso, Tullio Jappelli, Laurence Kotlikoff, Gerard Llobet, Robert Margo, Laura Moretti, Dilip Mookherjee, Marco Pagano, Daniele Paserman, Jeremy Smith, Adrien Verdelhan and the seminar participants at Boston University, University of Salerno, CSEF, LUISS Guido Carli and EIEF for helpful comments. All remaining errors are mine.

\section{References}

Acemoglu, Daron and Thierry Verdier. 2000. The Choice Between Market Failures and Corruption. American Economic Review 90, 194-211.

Almeida, Rita and Pedro Carneiro. 2005. Enforcement of Labor Regulation, Informal Labor and Firm Performance. World Bank Policy Research Working Paper 3756.

Amaral, Pedro S. and Erwan Quintin. 2006. A Competitive Model of the Informal Sector. Journal of Monetary Ecnonomics 53, 1541-1553.

Antunes, Antonio R. and Tiago V. de V. Cavalcanti. 2007. Start-Up Costs, Limted Enforcement, and the Hidden Economy. European Economic Review 51, 203-224.

Auriol, Emmanuelle and Michael Warlters. 2005. Taxation Base in Developing Countries. Journal of Public Economics 89, 625-646. Azuma, Yoshiaki and Herschel I. Grossman. 2002. A Theory of the Informal Sector. NBER working paper 8823.

Beck, Thorsten and Asli Demirguc-Kunt. 2006. Small and Medium Sized Enterprises: Access to Finance as a Growth Constrain. Journal of Banking and Finance 30, 2931-2943.

Becker, Gary. 1968. Crime and Punishment: an Economic Approach. Journal of Political Economy 76, 169-217.

Bertrand, Marianne and Francis Kramarz. 2002. Does Entry Regulation Hinder Job Creation? Evidence from the French Retail Industry. Quarterly Journal of Economics 107, 1369-1413.

Besley, Timothy and Robin Burgess. 2004. Can Labor Regulation Hinder Economic Performance? Evidence from India. Quarterly Journal of Economics 119, 91-134.

11 An example is provided by De Paula and Scheinkman (2008). They highlight the role of the value added tax, typically administered through tax credit schemes, at spreading informality to the buyers and sellers of an informal firm. 
Blackburn, Keith, Niloy Bose and Salvatore Capasso. 2012. Tax Evasion, the Underground Economy and Financial Development. Journal of Economic Behavior \& Organization 83: 243-253.

Blanchard, Olivier and Francesco Giavazzi. 2003. Macroeconomic Effects of Regulation and Deregulation in Goods and Labor Markets. Quarterly Journal of Economics 118, 879-907.

Botero, Juan C., Simeon Djankov, Rafael LaPorta, Florencio Lopez-De-Silanes and Andrei Shleifer. 2004. The Regulation of Labor. Quarterly Journal of Economics 119, 1339-1382.

Busato, Francesco and Bruno Chiarini. 2004. Market and Underground Activities in a Two-Sector Dynamic Equilibrium Model. Economic Theory 400: 1-31.

Capasso, Salvatore and Tullio Jappelli. 2013. Financial Development and the Underground Economy Journal of Development Economics 101, 167-178

Caselli, Francesco and Nicola Gennaioli. 2008. Economics and Politics of Alternative Institutional Reforms. Quarterly Journal of Economics 123, 1197-1250.

Choi, Jay Pil and Marcel P. Thum. 2005. Corruption and the Shadow Economy. International Economic Review 46, 817-836.

Dabla-Norris, Era, Mark Gradstein and Gabriela Inchauste. 2008. What Causes Firms to Hide Output? The Determinants of Informality. Journal of Development Economics 85, 1-27.

Davis, Steven J. and John Haltiwanger. 1992. Gross Job Creation, Gross Job Destruction and Employment Reallocation. Quarterly Journal of Economics 107, 819-863.

Davis, Steven J. and Henrekson, M. 2004. Tax Effects on Work Activity, Industry Mix and Shadow Economy Size: Evidence from Rich Country Comparisons. NBER Working paper 10509.

De Paula, Aureo and Jose A. Scheinkman. 2008. The Informal Sector. Penn Institute for Economic Research working paper 08-018.

D’Erasmo, Pablo N. and Moscoso Boedo Hernan J. 2012. Financial Structure, Informality and Development. Journal of Monetary Economics 59, 286-302.

De Soto, Hernando 1989. The Other Path. New York: Harper and Row.

Dessy, Sylvain and Stephane Pallage. 2003. Taxes, Inequality and the Size of the Informal Sector. Journal of Development Economics 70, 225-233.

Djankov, Simeon, Rafael LaPorta, Florencio Lopez-De-Silanes and Andrei Shleifer. 2002. The Regulation of Entry. Quarterly Journal of Economics 117, 1-37.

Djankov, Simeon, Rafael LaPorta, Florencio Lopez-De-Silanes and Andrei Shleifer. 2003. Courts. Quarterly Journal of Economics 118, 453-517.

Dunne, Timothy, Roberts, Mark J. and Larry Samuelson. 1989. The Growth and Failure of U. S. Manufacturing Plants. Quarterly Journal of Economics 104, 671-698.

Estrin, Saul and Tomasz Mickiewicz. 2012. Shadow Economy and Entrepreneurial Entry. Review of Development Economics 102, 559-578.

Evans, David S. 1987. Tests of Alternative Theories of Firm Growth. Journal of Political Economy 95, 657-674.

Friedman, Eric, Simon Johnson, Daniel Kaufmann and Pablo Zoido-Lobaton. 2000. Dodging the Grabbing Hand: The Determinants of Unofficial Activity in 69 Countries. Journal of Public Economics 76, 459-493.

Fugazza, Marco and Jean-Francois Jacques. 2003. Labor Market Institutions, Taxation and the Underground Economy. Journal of Public Economics 88, 395-418.

Gerxhani, Klarita. 2004. The Informal Sector in Developed and Less Developed Countries: A Literature Survey. Public Choice 120, 267-300.

Giles, David E.A. 1999. Measuring the Hidden Economy: Implications for Econometric Modeling. The Economic Journal 109, 370380.

Hirschman, Albert 0. 1970. Exit, Voice and Loyalty. Cambridge: Cambridge University Press.

Hopenhayn, Hugo 1992. Entry, Exit and Firm Dynamics in Long Run Equilibrium. Econometrica 60, 1127-1150.

Hopenhayn, Hugo and Richard Rogerson. 1993. Job Turnover and Policy Evaluation: A Genaral Equilibrium Analysis. Journal of Political Economy 101, 915-938.

Jovanovic, Boyan 1982. Selection and the Evolution of Industry. Econometrica 50, 649-670.

Johnson, Simon, Daniel Kaufmann, D. and Andrei Shleifer. 1997. The Unofficial Economy in Transition. Brooking Papers on Economic activity, 159-221.

Johnson, Simon, Daniel Kaufmann and Pablo Zoido-Lobaton. 1998. Regulatory Discretion and the Unofficial Economy. American Economic Review Papers and Proceedings 88, 387-392.

Klapper, Leora, Luc Laeven and Raghuram Rajan. 2006. Entry Regulation as a Barrier to Entrepreneurship. Journal of Financial Economics 82, 591-629.

Koreshkova, Tatyana A. 2006. A Quantitative Analysis of Inflation as a Tax on the Underground Economy. Journal of Monetary Economics 53, 773-796.

Lacko', Maria. 1999. Hidden Economy and Unknown Quantity? Comparative Analysis of Hidden Economies in Transition Countries. Univ. of Linz Working Paper.

La Porta, Rafael and Andrei Shleifer. 2008. The Unofficial Economy and Economic Development. Brookings Papers on Economic Activity 2008, 275-352. 
Lemieux, Thomas, Bernard Fortin and Pierre Frechette. 1994. The Effect of Taxes on Labor Supply in The Underground Economy. American Economic Review 84, 231-254.

Loayza, Norman. 1996. The Economics of the Informal Sector: a Simple Model and Some Empirical Evidence from Latin America. Carnagie-Rochester Series on Public Policy 45, 129-162.

Maloney, William. 2004. Informality Revisited. World Development 32, 1159-1178.

OECD. 2003. Measuring the Non Observed Economy: a Handbook. Paris: OECD.

Ordonez, Julio C. L. 2014. Tax Collection, the Informal Sector, and Productivity. Review of Economic Dynamics 17, $262-286$.

Prado, Mauricio. 2011. Government Policy in the Formal and Informal Sectors. European Economic Review 55, 1120-1136.

Sarte, Pierre-Daniel G. 2000. Informality and Rent Seeking Bureaucracies in a Model of Long Run Growth. Journal of Monetary Economics 46, 173-197.

Schneider, Friedrich. 2004. Shadow Economies Around the World: What Do We Really Know? European Journal of Political Economy 21, 598-642.

Schneider, Friedrich and Dominik H. Enste. 2000. Shadow Economies: Size, Causes and Consequences. Journal of Economic Literature 38, 77-114.

Straub, Stephane. 2005. Informal Sector: the Credit Market Channel. Journal of Development Economics 78, 299-321.

Tanzi, Vito 1983. The Underground Economy in United States: Annual Estimates 1930-1980. IMF staff paper 30, 283-305. 